\title{
Democratizing and Dehegamonizing Literature*: Endeavours of Empowerment
}

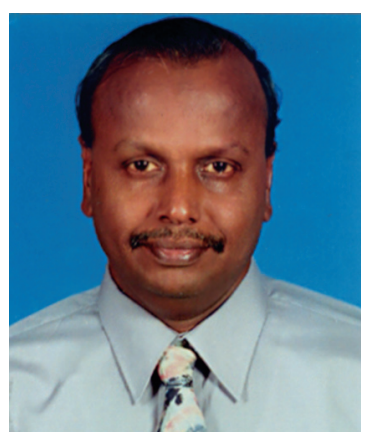

Sivakumar

Sivasubramaniam

\section{A Point of Departure}

The rampant prevalence of a technological-rationalist stance in our educational settings has done more harm than good to the use of literature in language teaching. Under its hegemony, the teaching of literature and writing about it have come to be viewed in narrow, reductive terms. In the 'interest of measurable efficiency' (Lehtovaara in Kohonen et al 2001:145) literature appears to have been increasingly subject to one right reading, received understanding and objectified rhetoric. This has set off a pernicious 'methodological scrupulosity' (Alter 1996:11) that has led our students to believe that the premises of discussion about literature are more important/valuable than the discussion of literature itself. Such a belief system neither allows our students to understand the edifying role of literature nor appreciate the sense of personal gratification it promotes. Therefore, 'a whole generation of professional students of literature have turned away from reading' (Alter 1996:11). How can we expect our students to invest in their personal engagement with literature when the very endeavour of teaching and writing about literature comes in their way of personalizing their experience of reading literature and the sense of agency it promotes? This is an educational malaise, which if left unchecked can weaken their capacity to understand how their world is affected by their reading and writing, and in turn how their reading and writing affect their world. In this respect, our students should be seen as illiterate even if they can read and write. This kind of illiteracy has far-reaching implications. It not only threatens the economic status of a society but also constitutes an injustice by preventing the illiterates from making decisions for themselves or from participating in the process of educational and social change. In short, it strikes at the foundations of democracy.

This poverty of reading and the culture of ignorance it creates need to be addressed in institutions of higher learning (McCormick 1994; Rosenblatt 1995). I hasten to suggest that by proposing a concept of literacy which encourages democratic and liberatory change, it might be possible to educate our students about the dialectical relationships between them and the world on the one hand, and language and change on the other (Freire and Macedo 1987). In light of this, literature pedagogies and practices that promote students' experience and response assume immediacy and primacy. It is argued that such pedagogies will teach our students to assert their rights and responsibilities. It will not only teach them to read, understand and transform their own experiences, but will also teach them to redefine their relationship with their society. As 
a result, our students will be better equipped to process knowledge that is beyond their experience and to view their reading and writing as acts of empowerment (Freire and Macedo 1987).

The issues discussed so far signpost my faith in the potential literature for nurturing critical consciousness, especially when delivered through pedagogies of response. However, most of us are fully aware as to how our institutional practices and dictates come in the way of implementing our well-informed choices. Many universities homogenize their teachers into teaching in a particular way and their students into learning in a particular way. This is because they believe that homogenizing their teachers and students into particular ways of functioning will provide for better control and power relations (McCormick 1994; McRae 1991).

The unrewarding and unchallenging institutional practices offer little or no scope for both the teacher and the students to reclaim their language both while reading literature and writing about it. In other words, neither the teacher nor the student will have an opportunity to reformulate their language of response and involvement. As a result, the teaching and learning of literature fails to develop critical consciousness in the classroom thereby promoting an illiteracy of disengagement. In order to promote learning through response and experience, we need to 'democratize and dehegamonize' the deployment of literature (Carter 1997:109) in our educational settings. Only then can we draw on the challenging content of literary texts to demolish the culture of ignorance and the illiteracy of disengagement created by a commodified approach to literature. I hope to address these matters in the following sections of this paper.

\section{What is Literature?}

We can see it as a body of written texts produced by a culture and valued within that culture. At another level, literature is seen as discourse. Such a view articulates the interpersonal/intersubjective nature of literature, which serves to illustrate how a particular way of language use is intrinsic to the social, economic, technological and theoretical needs of the cultures concerned (Fowler 1981).

If we accept Fowler's view of literature, then we should see it as a social artifact constructed and validated within the discourse practices of a society. Viewed from a constructivist standpoint, literature as social discourse could be instrumental in promoting interpretive discourse among our students and, as a result, democratize and free literature from its exclusionist and elitist shackles (Carter 1997:109).

Literary critics and linguists have always raised serious issues regarding the division between language and literature. While literary critics uphold the centrality of literary criticism, the linguists have been critical of the deviant use of language in literature and the privileged status accorded to it. The current adherence to metadiscourse centered approach to literature appear to favour such practices that emphsise the premises for 'about talking about literature' rather than talking about a reading experience of literature.

Jacobson (1960) has made an attempt to synthesize these conflicting views in his paper, 'Linguistics and Poetics' (Lodge 1988: 32-57). The paper states that 'A linguist 
deaf to the poetic functioning of language and a literary scholar indifferent to linguistic problems and unconversant with linguistic methods are equally flagrant anachronisms'.

Jacobson's view suggests that literature, primarily, is to be taken as text, as discourse. The language of literature is the medium through which a writer conveys a message about reality to the reader. Proceeding along this line of inquiry; Jacobson suggests that 'literariness', meaning, the language of literature is its poeticity. It is like oil in cooking. It cannot be had on its own. But when used with other foods, it is more than a mere addition; it changes the taste of the food to the extent that some dishes no longer appear to have any connection with their oil-less ingredients. This is to suggest that there is some connection between poeticity (i.e. literariness) and reality.

The connection between poeticity and reality might serve to illustrate the indestructible link between the human mind and the figurative aspects of language and thought (Gibbs 1994). As my position rejects an exclusive/isolationist view of literature, it looks upon the notion of literariness as one of disposition brought to bear upon the text by the reader. If this position is accepted, then one needs to accept that literature with a capital ' $\mathrm{L}$ ' - canonical literature, and literature with a small ' 1 ' - non-canonical texts ranging from proverbs to advertisements, could co-exist (Carter 1997; McRae 1991).

Teachers, who support an exclusive view of literature, (one in which canonical texts reign supreme) might view this co-existence offending. However, it is argued that the canonical status of literature is not as important as the creative and imaginative potential of literature in facilitating an emotional engagement with the target language for the L2 learner. Given that literary language is patterned in creative play, the emotional involvement of the reader results in creative and imaginative interpretation of the words and structures, which sets it apart from a literal reading (Carter 1997).

In the post-modernist/deconstructionist age, the hegemony of the classical cannon has been challenged and its reverential status has been rendered untenable. Today, our view of what literature is has been expanded to 'include feminist and gay writing, genres such as detective fiction and horror, and - most notably-the new literatures developing in countries such as India and Singapore...'(Maley in Carter and Nunan 2001:181). Furthermore as observed by Alter (1996:19), 'Literature is not just a self-referential closed circuit but it is connected in meaningful and revelatory ways with the world of experience outside the text'. If we accept this position, then, the weighty historical and cultural baggage which assume centrality in canonical approaches to literature are not only irrelevant but are also not so useful in signposting the attractiveness, colour and magic of literary language. In light of this, we need to recognize the frequent occurrences of literary devices such as parallelism, rhyme, rhythm and metaphor in adverts, graffiti, public notices and even television soap-operas. The immediacy and relevance in these texts are easy for our students to understand (Maley in Carter and Nunan 2001).

The provisionality of these interpretation provides scope for multiple readings through renegotiated discourse, which in turn might serve to rehearse the readers' meaning-negotiating capacity. Therefore, I situate literature in tentative readings of text and discourse rich in creativity and imagination (Carter 1997; Sivasubramaniam 2004). 


\section{Imaginative Language/Literary Language and its Place in Human Existence.}

Having attempted a view of literature that frees it from an elitist/exclusionist view, I propose to focus on the role of imagination and how its unavoidable prevalence in literary language confers agency and voice to human existence in this section of the paper.

Britton (1993) claims literature can be assigned its rightful place by understanding the continuing role of creative language in our everyday life and its intrinsic link to human existence. Vygotsky (1978:93) explains how this creative language represents a transition from make-believe behaviour to imagination: "Imagination is a new psychological process for the child; it is not present in the consciousness of the very young child, is totally absent in animals, and represents a specifically human form of conscious activity. Like all functions of consciousness, it originally arises from action. The old adage that child's play is imagination in action must be reversed: we can say that imagination in adolescents and school children is a play without action".

The above quotation serves to illustrate the developmental link between makebelieve play in infancy and the practice of all the arts at all stages from childhood to the grave. This link, which could be formulated in many different ways, is characterized by Piaget (1951:155) as 'symbolic assimilation' and is reassigned into thought as imagination. Vygotsky (1978) is of the view that the poet does the same things as the child at play in that he/she creates a topsy-turvy world which he/she views with animated joy and delight and deliberately sets it apart from reality.

Continuing on this line of analysis, Vygotsky points out that by dragging a child into this topsy-turvy world we provoke his/her intellect as a preparation for mastering the laws regulating the real world. Although rhymes and stories are rich in this effect, they will only serve a diminishing purpose as the child matures into adulthood. T.S.Eliot's poem entitled "Animula" (Britton 1993:7) shows how the imperatives of 'is' and 'seems' weaken over time.

Vygotsky suggests that, while adults have no such conditioning of 'seems' over 'is' to contend with, there is a similar duality for them to see in any form of art. Art serves to modify and distort perceptions of reality, and by doing so strengthens the viewer's understanding of reality, at the same time helping the viewer to explore the structures of 'what might become'. This perspective is very much akin to what John Stuart Mill (Britton 1993:1) has said 'That which enables us, by a voluntary effort to conceive the absent as if it were present, the imaginary as if it were real, and to clothe it in the feelings which, if it were indeed real, would bring along with it.'

Viewed in light of the above-mentioned insights, literature by signposting the language of imagination and creativity, not only becomes an art but also a way of building life. The paper considers this underpinning particularly important to an expressivistprocess approach to reading literature, as it has a large store of pedagogical benefits for the learner. It is only through a reading of literature and responding to it that students come to know and realize how human development and creative use of language are inextricably intertwined (Vygotsky 1978). Such an edifying realization is often lost when students of literature are trapped in a 'hermeneutics of suspicion' (Alter 1996:11), which makes them feel disenfranchised about their encounter with the literary texts. 
The notion that meaning is created through interpersonal and interactional exchanges presupposes the futility of an isolated self signifying 'the objective' at the expense of 'the social' (Vygotsky 1978) and 'the creative'. The same notion finds an equally succinct expression in the French philosopher, Georges Gusdorf (1965:48): "In essence, language is not one but of many; it is between. It expresses the relational being of man.... The self does not by itself alone have to carve out for itself an access to being-because the self exists only in reciprocity with the other".

Volisnov (1973: 118) in providing a corollary to this view claims: "Everything vital to the evaluative reception of another's utterance, everything of ideological value, is expressed in the material of inner speech. After all, it is not a mute, wordless creative that receives the utterance, but a human being full of inner words. All his experiences.... exist encoded in his inner speech and only to that extent do they come into contact with speech received from outside. Word comes into contact with word".

This perspective locates encoding in biological, psychological and social aspects of life reflected in a process of individual responsibility. Besides the biological, psychological and social influences on what has been encoded, there is a possibility that a person's changing conception of the world could either shrink or expand the encoding. If our students' responses/reactions to literature fail to reflect this, then teaching and writing about literature becomes pointless.

I will now focus on I.A. Richard's "Practical Criticism: A Study of Literary Judgement" (1935) to cite a real-life situation that can illustrate the dangers of trained appreciation and judgement of literary texts. I believe that this can further strengthen the belief and value systems underpinning my paper.

I.A. Richards asked his class at the University of Cambridge to write responses and reactions to some unidentified poems. He avoided giving clues to title, authorship, period, and school, as he wanted to test his students' capacity to engage with poetry through personal response. The students were expected to base their responses on their own sense of engagement with the poems. Most of the students found their experience with the poems bewildering as their training in literary traditions, critical approaches, and judgemental methods was of little or no use in their handling of their plain responses. As a result, their responses showed a barrier to understanding and appreciating the poems in spite of the specialist training they had received. Their writing indicated how exposure to ready-made responses and associations interfered with their personal sense of literature. This can be further supported by Rosenblatt's (1995:92) observation that 'the impact of the literary work is dulled when the reader brings to the text a fund of ready-made, sharply crystallized ideas and habits of response.'

The points discussed so far have served to explain the purpose of literature and the dangers that can accrue when the interpersonal and intersubjective credentials of literature are discarded in favour of those approaches that objectify literature. If one accepts the poetics of mind, that is, the capacity of the human mind to produce and engage in creative thought and language (Gibbs 1994), then one should trust in the power of literature which employs imaginative language to assign meaning and purpose to our existence (Britton 1993; Vygotsky 1978; Gibbs 1994; Langer 1992; and Rosenblatt 1978, 1995). 


\section{Perceptions, Priorities and Procedures Ahead.}

The discussion so far has articulated the urgent need for the fostering of interpersonal and intersubjective discourse in the practice of literature teaching. Does this mean that it is possible to process literary expression without any reliance on trained analytic attention? As illustrated earlier (see the preceding section), it is possible to do so because 'we read literature with the same set of complex skills we use to read newspapers, legal rulings, menus, advertisements...'(Alter 1996:23). This is to suggest that there are strong commonalities and complementarities between the ways by which we read literary texts and the ways by which we read other types of texts. We do not require specialized training, 'like taking courses in Sanskrit or calculus, in order to make sense of the simplest story or poem' (Alter 1996:24).

In order to democratize literature, we need to subvert/challenge the belief system that upholds the 'self-sufficiency' and 'referential stability' (Mackenzie 2002:46) of the literary text. Only then can we free a literary text from its author's words in order to signpost the creative consciousness that operates behind it. Such a position opens the door to 'applicative reading' (Mackenzie 2002:46), which can empower our student readers of literature to interpret it according to their own beliefs and desires. The ensuing vibrant accrual of a plurality of meaning can assign a new sense of agency and voice to the reading process undertaken by our students (Rosenblatt 1995). In light of this, literature, which is often viewed as a product that contains objective meanings is transformed into a robust productive process. Such a transformation dispels the author's reverential status in the text as an arbiter of objective meanings, thereby freeing the reader from following the roles and conventions prescribed by the text. As a result, literary reading need not limit itself to attempted communication, one in which a heuristic stimulus for the creation of new meanings overwhelm the compulsions of recovering a particular set of explicatures and implicatures contained in the text (Mackenzie 2002:46).

By accentuating the role of the reader and his/her personal sense of literature, we lay the groundwork for a personal enrichment approach to literature, which will free literature from its exclusivist shackles. This approach uses literary texts to promote a personal sense of literature in students. By providing an emotional and intellectual engagement with literary texts, this approach fosters a personal sense of involvement in students. As this sense of personal involvement develops, students begin to look upon reading literature as a gratifying experience. The scope for group work through frequent interactions is a key feature of this approach. It is argued that the emotional security provided by group work to students can make them feel emotionally secure rather than feel intimidated in their encounters with literary texts. When their personal sense of involvement strengthens, it can promote learner autonomy in them with which they can make independent explorations into texts. Texts/materials used in this approach reflect students' interest and its link to personal involvement. The presence of theme-based texts in the approach alerts us to the potential they have for addressing educational and social concerns (Lazar 1993; Freire and Macedo 1987; Rosenblatt 1995). 
Democratizing literature in the educational practices of reading and writing requires the support of a learner-centred educational ideology, which views education as a way of empowering learners to teach themselves how to learn. Synonymous with progressivism, such an ideology articulates the centrality of experience to learning and the outcome of that learning as growth. Viewed in light of this ideology, knowledge assumes speculative and perspectival attributes (Clark 1987). So, it cannot be value-free and close-ended as seen by the traditional approaches to literature reminiscent of classical humanism and reconstructionism. As an open-ended approach to knowledge, progressivism makes for emotionally and socially enriching learning experiences, which help the learners to view themselves as whole persons rather than fragmented individuals. Such a process is important to this undertaking as it opposes homogenizing students on the basis of norm-referenced learning and assessment (Clark 1987; Nunan, 1988). Therefore, personalizing learning through a personalizing approach to literature becomes the most important priority for this inquiry. It is hoped to discuss this further in terms of the pedagogy of response to be proposed in the subsequent sections of this paper.

A personalizing approach to literature necessitates the learners' active involvement with it, by which the learner becomes an active participant in the learning process. This is in contrast to the passive role assigned to the learner in classical humanism and a subservient role demanded of the learner in reconstructionism (Sivasubramanaim 2004). The active role envisaged for the learner encourages the learner to react to and reflect on learning process. Such a role can help both the learner and the teacher to take an associative/negotiative view of learning and assessment. In this regard, the learner finds it an educating experience to voice and share his/her perceptions of what has been learned. As a result, learning and assessment become a learner-centred undertaking. This is not to suggest that the teacher will assess the learner as the learner wishes to be assessed. But it is to suggest that the participatory role of the learner can make him/her take responsibility for learning and take control of how the learning tasks and strategies proposed by the teacher should be handled (Clark 1987; Nunan 1988). The concern for learner involvement and autonomy expressed by progressivism can be matched with its similar emphasis on empowering teachers into becoming reflective practitioners.

Very often teachers carry out the choices and pre-determined objectives of a curriculum designed by someone else. Because of this they do not critically examine the role of the curriculum and their role in deploying it. An uncritical engagement with the curriculum reduces their teaching role to that of a perfunctory task. As a result teachers become 'curriculum clerks carrying out other people's decisions about subject matter and classroom management' (Delawter 1992:101). In the light of this, the progressivist emphasis on teacher empowerment leads teachers to believe that they need to voice their professional beliefs and concerns in order to consider and construct new perspectives on their role as teachers. It is argued that metaphors in current educational use liken educational practices to those followed in the fields of business, computer industry and the military. Such a likening projects educational practices as prescribed systems to be followed with utmost care. As a result the teachers' role gets basalized (Smith 1988). It 
is further argued that there is urgent need to discard the teacher as a curriculum clerk metaphor and put in its place the teacher as an explorer metaphor. Such a metaphor can reinforce the progressivist concern for teacher empowerment through reflective teaching practice. By voicing their beliefs and concerns, teachers can experience a sense of freedom. This sense of freedom can alert them to new alternatives to perspectives on their teaching practices. Thus they can become explorers of knowledge through reflective teaching practice (Smith 1988) if literature is democratized and dehegamonized from its exclusivist shackles.

At this juncture, it should be stressed that promotion of literature in society is contingent on the teachers' belief in its educational and social values for the students. In the light of this point, when teachers empower themselves into becoming questioning professionals, they will encourage their learners to empower themselves into becoming questioning citizens.

The issues and insights discussed so far signpost a process-centred view of reading and writing about literature as the mainstay of a pedagogy of experience and response that has assumed special prominence and substance in this paper. Viewed in the light of the attitude and beliefs underlying my stance, received knowledge, pre-determined learning behaviour, tutored learning in the guise of focused instruction and norm-based assessment of goals, and are believed to be detrimental to current educational practices. The following views of Skilbeck (1982:20) support my rejection of classical humanism and reconstructionism: "Externally imposed syllabuses, text books, and examinations all define educational values and set certain standards which are important from the standpoint of the individual as well as for national and social purposes; however, they make the spontaneity, flexibility and diversity which are an equally important part of education much more difficult to achieve".

It is argued that spontaneity, flexibility and diversity can accrue only through a process-centred pedagogy of response. A prolonged neglect of spontaneity, flexibility and diversity in the literature/language classroom will not only impede the democratization of literature but will also hasten its extinction. Therefore, it should be noted that progressivist concerns would determine the form and substance of the pedagogy of response that is central to this undertaking. Such a position is consistent with a constructivist epistemology that underpins our approach to democratizing literature.

At this juncture, I wish to stress that the process-centred approaches to learning have thrown up a new emphasis, which has come to be known as constructivism (Applebee 1992: 12-16). Constructivism can be looked at metaphorically and philosophically. As a metaphor, it means understanding knowledge and learning through experience. As a philosophy of learning it emphasizes the premise that by reflecting on our experiences we construct our own understanding of the world we live in. In doing so, we make sense of our experiences by constructing our own mental models to interpret new experiences (Reagan 1999; Osborn, 2000).

Constructivism as a philosophy of learning opposes transmission-based approaches to literature. In this regard it challenges the tenets of classical humanism and 
reconstrustionism. In a constructivist model of learning, learners personalize their experiences in order to construct knowledge. It should be recalled here that this position is consistent with the living through experience by students and the telling of the story of reading by them in the process of aesthetic reading as envisaged in reader response approaches to literature (Rosenblatt 1995).

The living through experience and the telling of the story of reading serve to exemplify the two strands of constructivist perspective: 1) radical constructivism and 2) social constructivism. Radical constructivism relates to knowledge as an outcome of the learner's active mental effort emphasized by the living through experience. Social constructivism relates to knowledge as an outcome of the learner's personal effort in a social cultural context where telling of the story of reading unfolds as a social event (Rosenblatt 1995; Reagan 1999; Osborn 2000). I believe that by synthesizing the two strands of the constructivist perspective we can facilitate a constructivist-learning environment for the deployment of a pedagogy of response. In light of this, I believe it will be helpful to visit the eight characteristics proposed by Jonassen (1994: 34-37) that describe a constructivist-learning environment which aim to synthesize the two strands of the constructivist perspective. Constructivist learning environments:

1. Encourage multiple representations of reality.

2. Avoid oversimplification to represent the complexity and diversity of the real world.

3. View knowledge as 'constructed' not as 'given'.

4. Emphasize authentic activities and meaningful contexts.

5. Focus on real world settings and non-linear instruction.

6. Provide stimulus for reflecting on experience.

7. Articulate context-bound characteristics of knowledge.

8. Acknowledge collaborative construction of knowledge through inter-personal associations/negotiations.

I hasten to suggest that these eight characteristics not only serve to reinforce all the key theoretical issues raised so far, but also necessitate an understanding of a problemposing model of education situated in a constructivist approach to literacy education proposed by Freire (1973). In order to understand 'the problem-posing model' we need to look at its antithesis, the banking-model of education. According to Freire the banking-model of education is one where the teacher's primary objective is to deposit information into students as they would deposit money into a bank. Such an approach as mentioned by Freire (1972: 46-47) has the following characteristics:

- The teacher teaches and the students are taught.

- The teacher knows everything and the students know nothing.

- The teacher thinks and the students are thought about.

- The teacher talks and the students listen.

- The teacher disciplines and the students are disciplined.

- The teacher chooses and enforces his choice and the students comply.

- The teacher acts and the students have the illusion of acting through the action of the teacher. 
- The teacher chooses the program content and the students adapt to it.

- The teacher confuses the authority of knowledge with his own professional authority, which he sets in opposition to the freedom of the students.

- The teacher is the subject of the learning process, while the pupils are mere objects.

These characteristics envisage an order of learning in which students are discouraged from finding out how and why they are being asked to do certain learning tasks because the teacher imposed them to be done. So it is unlikely that they will feel involved or engaged with the learning tasks. Thus they pick up on a survival orientation, which directs them to believe that passing a course is the primary objective of their learning. Such a belief not only defeats the purpose of education but also feeds into a culture of illiteracy as pointed out earlier.

The problem-posing model of education encourages a dialogic nature of learning. This means that the teacher and the student interact with each other as 'knowledgeable equals in a situation of genuine two-way communication' (Freire 1972:52-59). Therefore, the lecture-based learning dominant in the banking model is replaced by a model in which teachers and students discuss issues of concern in their lives in a nonthreatening encounter. The use of themes in the form of open-ended texts provides unrestricted scope for discussing and problematizing the issues seen in the texts. The open-ended questions encourage students to elaborate and hypothesize on what they see in these texts. Thus, the process discussed here can reverse the culture of illiteracy by teaching students to read the world. Such an outcome is not only vital to literature education but also central to our understanding of the efficacy of literature in our educational and social process (Freire 1972, 1973). Therefore, the problem-posing model of education and its constructivist underpinnings assume centrality in our undertaking to democratize literature. As a result, we are now better placed to understand the curricular shift that is required and along with that, the perceptions and procedures for democratizing and dehegamonizing literature from its exclusivist shackles.

\section{Signposting a Curricular Shift.}

The problem-posing model of literature education demands a curricular shift in order to maximize its beneficial outcomes. This according to Schon (1983: 333) will view the literature curriculum as: “....an inventory of themes of understanding and skill to be addressed rather than a set of materials to be learned. Different students present different phenomena for understanding and action. Each student makes up a universe of one, whose potentials, problems and pace of work must be appreciated as the teacher reflects-in-action on the design of her work".

Such a curricular position will conceptualize each reader as 'a universe of one' dispelling the notion of the normative responses to literary texts that overwhelm traditional approaches to literature. As such it can answer several questions that underlie our agenda for democratizing and dehegamonizing literature:

1. What different processes operate during reading/writing?

2. What types of responses are readers likely to make? 
3. What orientations do readers bring to literary texts?

4. How has their awareness of textual and social conventions and their reading encounters at home and in class influenced their responses?

5. What types of strategies do they use in responding to literature?

6. How does their knowledge, ability, attitude, interest, personality or purpose influence their responses?

As a sequel to above mentioned points, I wish to question the notion of nativespeaker competence, which presupposes that native speakers have the requisite linguistic, literary and cultural competence to read texts and write about them. This may not be true if viewed from a perspective of interpretive literacy, which is analogous to a capacity for reading the world. The problem of literacy for native language as well as foreign language readers is that there is no uniform competence. As Kern observes (2000: 116): "All interpretation is partial because all competence is partial. Foreign language readers need not see themselves as hopelessly handicapped by their 'outsideness' with respect to the texts they read. On the contrary, their very outsideness can provide them with insights that would not necessarily occur to 'native' readers. When learners feel that the knowledge they can bring to a particular text is illegitimate or inappropriate, they will feel like keeping their interpretations to themselves. What teachers need to do, therefore, is to motivate learners to share their varied interpretations in order to make them aware of how all reading is mediated experience, and that many factors will contribute to the particular ways in which that mediation takes place during a given act of reading".

I am aware at this juncture that there are many dimensions to writing and individuals can be found at different points on each dimension. So we should never assume, as Smith (1982: 5) observes 'that the way we ourselves write is the way everyone writes. Teachers must not assume that their own idiosyncrasies are the only or even the best way to write.'

Writing, like the language, can contribute to every aspect of our lives. It can extend and reflect our efforts to develop and express ourselves in the world. Any mystification that regards writing about literature as an esoteric skill that only a few can master at the cost of great effort, should be dismissed. The benefit of writing extends to anyone who can speak and read (Smith 1982). By the same token it is unbeneficial to view writing as a special kind of activity that requires exceptional talents or extensive training and one which can be used for specialized ends that might concern select individuals.

Writing not only requires reading for its completion but also promotes the kind of reading it requires (Lodge 1977). Given that both first and second language writing involve similar processes (Kern 2000), we need to adopt a sympathetic/positive attitude rather than a dismissive/punitive attitude to students' writing about literature. So accuracy and objectivity in writing should not be a cause for concern in the scheme of things proposed in this paper. To this effect, motivational factors and personal response factors should be tuned to initiate students into writing. In order to inspire students to write, we can use situated practice, that is, the students' immersion in writing as an act of designing meaning rather than fulfilling a mechanistic act of literary response predicated on trained use of 
conventions such as grammar, vocabulary and syntax (Kern 2000; Smith 1982). Through situated practice, we can facilitate immersion techniques, which will foster free writing, response chronicles and dialogue/response journals. Over a period of time these interactive, facilitative, negotiative and associative investments can evolve into cooperative classroom literature, which will not only humanize students' involvement with literature, but will also aggrandize its merit and lasting value in our educational practices.

\section{Some Possible Outcomes.}

Democratization of literature envisages an order of learning and teaching literature, which can help promote the following outcomes:

1. It might reduce the examination-oriented mentality and take reading beyond mere performance in an examination.

2. It might emphasize reading as a space for the exercise of mental energy and creativity.

3. It might initiate an understanding of the exigencies of text and student, and above all, of communication.

4. It might instill a love for books in students by which it is hoped, it will encourage them to acquire books for themselves both for their own enjoyment and for their longer term education benefit, as their range of reading expands.

5. It might encourage students to explore other texts, which might not have been read in class and to start building up a library of books they are happy to own.

6. It might foster a high degree of reader autonomy which will not only develop extensive reading but will also take them far beyond the imaginative learning benefit of the original classroom encounter with the texts.

7. It might use reading as a valuable input to develop writing as a response to reading.

8. It might help students discover the personal utility of writing and the life-long joys and delights associated with writing.

When viewed from a soco-psychological perspective, the process of learning literature in a second language itself takes on special significance. From this viewpoint (Lambert, et al 1960), one would expect that, if the student is to be successful in his/her attempt to learn another social group's language he/she must be both able and willing to adopt various aspects of behaviour, including verbal behaviour, which characterizes members of the other linguistic-cultural group. Democratization of literature will promote receptivity to the experience of becoming a speaker/reader/writer of another language or somebody else's language. It will encourage the teachers to shed their traditional pedagogue image and take on the role of facilitators who would be keen to deal with their students on a first-name basis. By doing so, the literature classroom will promote receptivity to the teacher as a person and by stressing group work in class, it hopes to promote receptivity to fellow learners notwithstanding the need to address the inter-ethnic or political prejudices of the learners by emphasizing diversity in class as a learning resource to the learners (Allwright and Bailey 1991). 
This journey of understanding has so far served to point out the urgent need to democratize the literary texts so as to reverse the culture of ignorance and illiteracy through a response-centered reading-the-world approach to literature. In light of this, it is argued that the educational and social developments of our students are inextricably linked to their reading and writing about literature. In this respect, the stultifying and disempowering role of a canonical approach to literature needs to be eliminated with the help of the issues and insights articulated in this paper. It is only through reading and provisional understanding of literary texts that our students can come to realize its transformative and the empowering influences on living and learning. Such a realization is crucial to the functioning of civilized societies and democracies. As Rosenblatt (1995: 171), observes: "Education in this era of social transformation must serve both critical and constructive ends. On the one hand youth need the knowledge and the intellectual tools required for critical appraisal of ideals and social mechanisms -new and old. On the other hand, youth need to develop positive emotional drives that will quicken intellectual insight. Thus they will be enabled to free themselves from antisocial attitudes and will be impelled to achieve a world that will safeguard human values".

Therefore a safeguarding of human values demands an assimilation of ideas and attitudes, which can only accrue through a personal and provisional reading of literary texts and writing about them. Needless to say that the prevalence of literature is fundamental to our educational practices, a well-informed democratization of the ways in which we encourage our students to read and write about what has been read will enhance all that we stand for as human beings in a world that is being increasingly characterized by a predominance of consumerism, corruption and moral/social decay.

\section{Notes:}

* The stimulus for this paper derives from Professor Carter's valuable insight discussed in his book "Investigating English Discourse", published in 1997. This paper was delivered as a sub plenary address at the Second International Conference of the Armenian Association for the Study of English (AASE), held at the Yerevan State University, Yerevan on 16 -19, October 2007.

\section{References:}

1. Alter, R. (1996) The Pleasures of Reading in an Ideological Age. New York: Norton.

2. Allwright, D.; Bailey, K.M. (1991) Focus on the Language Classroom. Cambridge: Cambridge University Press.

3. Applebee, A.N. (1992) The Background for Reform. // Literature Instruction: Focus on Student Response. / Ed. by Langer, J.A. Urbana, Illinois: NCTE.

4. Britton, J. (1993) Literature in its Place. Portsmouth New Hampshire: Boynton/Cook-Heinemann. 
5. Carter, R.A. (1997) Investigating English Discourse. London: Routledge.

6. Clark, J. (1987) Curriculum Renewal in School Foreign Language Learning. Oxford: Oxford University Press.

7. Delawter, J. (1992) Teaching Literature: From Clerk to Explorer // Literature Instruction - a Focus on Student Response. / Ed. by Langer, J.A. Urbana, Illinois: NCTE.

8. Eliot, T.S. (1936) Collected Poems, 1909-1935. London: Faber \& Faber.

9. Fowler, R. (1981) Literature as Social Discourse: The Practice of Linguistic Criticism. London: Batsford.

10. Freire, P. (1972) Pedagogy of the Oppressed. New York: The Continuum Publishing Corporation.

11. Freire, P. (1973) Education for Critical Consciousness. New York: The Continuum Publishing Corporation.

12. Freire, P. (1987) The Importance of the Act of Reading // Freire, P.; Macedo, D. Literacy: Reading the Word and the World. Ct: Bergin and Garvey.

13. Freire, P.; Macedo, D. (1987) Literacy: Reading the Word and the World. Ct: Bergin and Garvey.

14. Gibbs, R.W. (1994) The Poetics of Mind, Figurative Thought and Language and Understanding. New York: Cambridge University Press.

15. Gusdorf, G. (1965) Speaking. Evanston, Illinois: Northwestern University Press.

16. Jacobson, R. (1960) Linguistics and Poetics // Modern Criticism and Theory: A Reader. / Lodge, D. (ed.). London: Longman.

17. Jonassen, D.H. (1994) Thinking Technology: Toward a Constructivist Design Model // Educational Technology. N34(4).

18. Kern, R. (2000) Literacy and Language Teaching. Oxford: Oxford University Press.

19. Lambert, W.E.; Hodgson R.; Goodner R.C.; Fillenbaum S. (1960) Evaluational Reactions to Spoken Language // Journal of Abnormal and Social Psychology, N60.

20. (1992) Literature Instruction: A Focus on Student Response. / Langer, J.A. (ed.). Urbana, Illinois: National Council of Teachers of English.

21. Lazar, G. (1993) Literature and Language Teaching. Cambridge: Cambridge University Press.

22. Lehtovaara, J. (2001) What is it - (FL) Teaching? // Kohonen, V.; Jaatinen, R.; Kaikkonen, P.; Lehtovaara, J. Experiential Learning in Foreign Language Education. Harlow: Longman.

23. Lodge, D.C. (1977) The Models of Modern Writing: Metaphors, Metonymy and the Typology of Modern Literature. Ithaca. New York: Cornell University Press.

24. Mackenzie, I. (2002) Paradigms of Reading. Basingstoke: Palgrave Macmillan.

25. Maley, A. (2001) Literature in the Language Classroom // The Cambridge Guide to Teaching English to Speakers of Other Languages. / Carter R.A.; Nunan D. (eds.). Cambridge: Cambridge University Press.

26. McCormick, K. (1994) The Culture of Reading and the Teaching of English. Manchester: Manchester University Press. 
27. McRae, J. (1991) Literature with a Small ' $l$ '. London: Macmillan.

28. Nunan, D. (1988) The Learner-Centred Curriculum. Cambridge: Cambridge University Press.

29. Osborn, T. (2000) Critical Reflection and the Foreign Language Classroom. Westport, Ct: Bergin and Garvey.

30. Piaget, J. (1951) Play, Dreams and Imitation in Childhood. London: Heinemann.

31. Reagan, T. (1999) Constructivist Epistemology and Second/Foreign Language Pedagogy // Foreign Language Annals, N32.

32. Richards, I.A. (1935) Practical Criticis: A Study of Literary Judgement. London: Kegan Paul, Trench, Trubner.

33. Schon, D. (1983) The Reflective Practitioner: How Professionals Think in Action. New York: Basic Books.

34. Sivasubramaniam, S. (2004) An Investigation of L2 Students' Reading and Writing in a Literature-Based Language Programme: Growing through Responding. Unpublished PhD Thesis UK, University of Nottingham.

35. Skilbeck, M. (1982) School-Based Curriculum Development // Planning in the Curriculum. / Lee, V.; Zeldin, D. (eds.) Sevenoaks: Hodder and Stoughton.

36. Smith, F. (1982) Writing and The Writer. Jordan Hill. Oxford: Heinemann Educational Books.

37. Smith, F. (1988) Misleading Metaphors of Education // Joining the Literacy Club. / Smith, F. (ed.) Portsmouth. New Hampshire: Heinemann Educational Books.

38. Volisnov, V.S. (1973) Marxism and Philosophy of Language. London: Seminar Press.

39. Vygotsky, L.S. (1978) Mind in Society: The Development of Higher Psychological Process. Cambridge. Massachusetts: Harvard University Press.

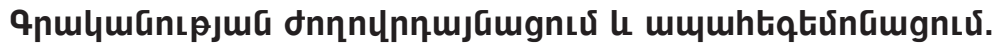

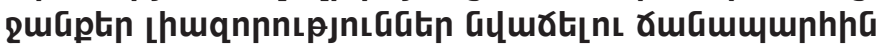

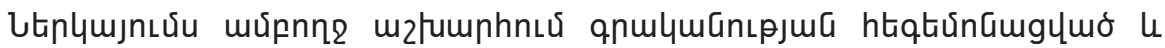
ธ̌

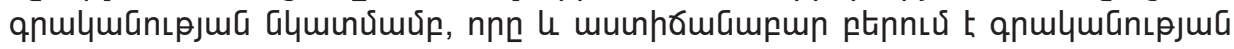

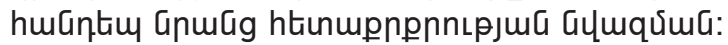

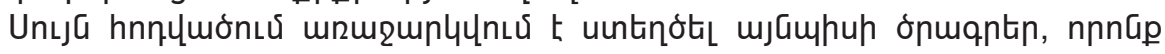

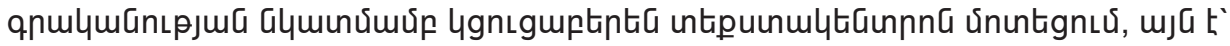

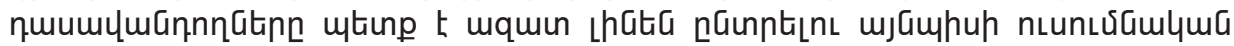

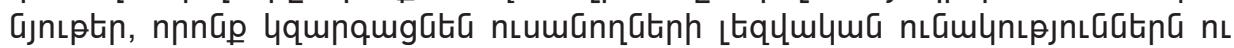

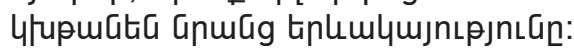

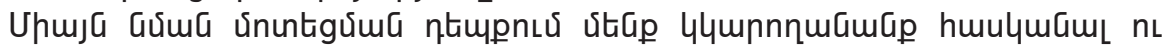

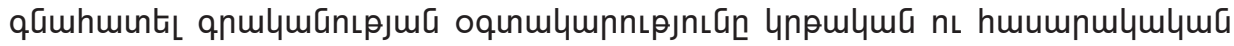
qnnơntatinıpJuG utį: 